Int. J. Dev. Biol. 57: 273-280 (2013)

doi: $10.1387 / \mathrm{ijdb} .130135 \mathrm{mb}$

\title{
Revisiting DNA damage repair, p53-mediated apoptosis and cisplatin sensitivity in germ cell tumors
}

\author{
FRANCESCA CAVALLO ${ }^{1,2}$ DARREN R. FELDMAN ${ }^{3}$ and MARCO BARCHI*,1 \\ ${ }^{1}$ Department of Biomedicine and Prevention, University of Rome Tor Vergata, Italy, ${ }^{2}$ Developmental Biology Program, \\ ${ }^{3}$ Department of Medicine, Memorial Sloan-Kettering Cancer Center, New York, NY, USA
}

\begin{abstract}
Testicular germ cell tumors (TGCTs), ie, seminomas and nonseminomas, account for $1 \%$ to $3 \%$ of all neoplasms in men. They are the most common cancer in young white males and are unique in their responsiveness to cisplatin-based chemotherapy. For this reason, TGCTs are considered a model for curative disease. However, up to now, the molecular mechanisms behind this exceptional responsiveness to DNA-damaging agents have remained unclear. A hypersensitive apoptotic response, as well as a reduction in the proficiency to repair cisplatin-induced DNA damage might account for this behavior. In this review, building on recent findings of p53-induced apoptosis and DNA-repair mechanisms in TGCTs, we will discuss the molecular bases that drive tumor sensitivity to cisplatin, emphasizing the new therapeutic approaches proposed to eventually constrain tumor recurrence, and target TGCTs which are unresponsive to standard therapies.
\end{abstract}

KEY WORDS: p53, XPF, ERCC1, homologous recombination (HR), nutlin-3, MDM2

\section{Introduction}

Testicular cancer constitutes the most common solid tumor to affect men between 15 and 40 years of age (Bosl and Motzer, 1997). Approximately $95 \%$ of primary testicular tumors arise from embryonic germ cells, either primordial germ cells (PGCs) or gonocytes, and as such, are more appropriately referred to as testicular germ cell tumors (TGCTs). Other more rare testicular neoplasms are derived from non-germ cell tissues such as the stroma (Sertoli and Leydig cell tumors) and lymphocytes (lymphomas). Rarely, germ cell tumors can arise outside the testis, typically in midline locations, with the mediastinum, retroperitoneum, and brain constituting the most common extragonadal primary tumor sites. This anatomical distribution is possibly related to the migration route of PGCs during embryogenesis (Wylie, 1999).

Although the majority of advanced TGCTs are curable by cisplatin-based chemotherapy, the biological basis of this exquisite sensitivity remains unclear. An improved understanding of such mechanisms could enable the identification of new molecular targets that play a role in the cisplatin resistance observed in a fraction of germ cell tumors and more commonly in tumors of somatic origin.

Cisplatin kill cells by damaging DNA. Following DNA damage, cells respond by activating a DNA-damage response that either leads the cell to repair the lesion promoting resistance to treatment, or die by the activation of the apoptotic response. Key players in this response are thus DNA-damage repair pathways and apoptosisinducing mechanisms. This review will focus on the pro-apoptotic role of p53 in the response of TGCT to cisplatin-induced DNA damage and will highlight recent discoveries linking a reduced efficiency of DNA repair with resultant enhanced p53-mediated pro-apoptotic response amongst TGCT, to their exquisite cisplatin sensitivity.

\section{Epidemiology}

The incidence of TGCTs is highly variable depending on the country, with Scandinavian countries displaying the highest incidence at nearly 10 per 100,000 whereas rates in Asian and African countries are less than 2 per 100,000 (McGlynn and Cook, 2009). However, the worldwide incidence of TGCTs has more than doubled over the past 40 years, and it is still increasing. In addition, $2 \%$ of patients will develop a second testicular primary TGCT (Fossa et al., 2005). Thus, although malignant tumors of the testis are rare, this trend highlights the importance of identifying the pathogenic mechanisms of their origin, and developing new therapies for

Abbreviations used in this paper: DDR, DNA damage response; DSB, double strand break; EC, embryonal carcinoma; GCT, germ cell tumor; ICL, interstrandcrosslink; TGCT, testicular germ cell tumor.

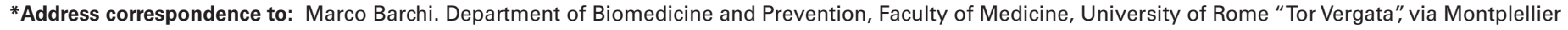
n.1, 00133, Rome, Italy. Tel: +39-06-7259-6266. Fax: +39-06-7259-6268. e-mail: marco.barchi@uniroma2.it web: http://www.med.uniroma2.it/content/ricercatori/barchi-marco

Final, author-corrected PDF published online: 5 June 2013.
}

ISSN: Online 1696-3547, Print 0214-6282 
patients who do not respond, or relapse to currently available chemotherapy regimens (see below).

\section{Pathology and pathogenesis}

Histopathologically, TGCTs can be classified in two major groups: seminoma and non-seminoma with the latter category also including tumors that contain both seminoma and nonseminoma components. Pure seminomas are composed of uniform, large polyhedral cells surrounded by connective tissue stroma. They comprise about $50 \%$ of TGCTs with a median age at diagnosis of 35 - 39 years. Non-seminomas, which also account for approximately $50 \%$ of cases are often comprised of a mixture of multiple cell types including embryonal carcinoma (EC), teratoma, choriocarcinoma, and yolk sac tumor. The median age at diagnosis of nonseminoma is about 10 years younger than seminoma, ranging from $25-29$ years of age. In order to be classified as seminoma, there cannot be any nonseminomatous component present in the tumor. Embryonal carcinoma has been demonstrated to be both undifferentiated and pluripotent and is considered the stem cell component of nonseminomas, analogous to a malignant form of embryonic stem cells.

All TGCTs originate from a precursor lesion, known as carcinoma in situ (Skakkebaek, 1972), also referred to as an intratubular germcell neoplasia unclassified (ITGCNU) lesions. The pathogenesis of ITGCNU lesions remain unknown but are most likely due to delayed or blocked maturation of PGC/gonocyte during development (Looijenga et al.). Several risk factors for TGCT have been identified. The most well-proven risk factor is being born with an undescended testicle (cryptorchidism), which occurs in approximately 3 of every 100 live male births (Moller and Skakkebaek, 1997). True cryptorchidism, however requires a lack of testicular descent by 6 months and when using this definition, the incidence drops to approximately 1 out of every 100 births. The risk of developing TGCT for patients with cryptorchidism approximates 10\% and approximately $10 \%$ of TGCT cases are also accounted for by men with a history of cryptorchidism (Kanto et al., 2004, Prener et al., 1996). Infertility (Lilford et al., 1994) and other forms of gonadal dysgenesis constitute additional risk factors for TGCTs (McGlynn and Cook, 2009). Prior diagnosis of TGCT also predisposes to development of a second TGCT in the contralateral testis. This occurs in about $2 \%$ of men with a first TGCT (Fossa et al., 2005). Additionally, patients with extragonadal germ cell tumors (GCTs) are at increased risk for developing TGCT, occurring in up to $6 \%$ of mediastinal primary GCT patients in one study (Hartmann et al., 2001). Maternal risk factors such as old age at pregnancy, and maternal in utero high level of estrogens, have been associated with the increased risk of TGCTs (McGlynn et al., 2008) indicating that the primary lesion likely occurs in PGCs/gonocytes in utero, possibly as part of the aforementioned testicular dysgenesis. Family history also portends a higher risk of TGCT development. For example, the risk among brothers of patients with TGCT has been estimated at 5-9 times that of an age-matched population. Familial aggregations of TGCTs have also been described (Greene et al.2010). Proposed genetic risk factors include specific abnormalities on the $Y$ chromosome(Anderson et al., 2009) and polymorphisms of KIT ligand and KIT signaling [13]. Furthermore, nearly all invasive TGCTs display gain of additional copies of the small arm of chromosome 12, most often as an isochromosome
(i12p)(Kanetsky et al., 2009, Korkola et al., 2009a, Korkola et al., 2009 b, Rosenberg et al., 2000), indicating that the relative overrepresentation of $12 p$ sequences is of crucial importance for the progression of this cancer. However, in spite of much effort, the relevant gene(s) have not been identified so far, although various candidates (including NANOG and KRAS2) have been suggested to play a role (for more details see Looijenga et al., 2011).

\section{TGCT treatment response to cisplatin}

Prior to the introduction of cisplatin in the mid-1970s, chemotherapy for GCTs was only minimally effective. In fact, GCTs were once the leading cause of cancer death among men between 15 and 34 years of age. Remission rates for patients with metastatic disease approximated only $25 \%$. In 1977, Einhorn and Donohue reported impressive results with a chemotherapy regimen comprised of cisplatin, vinblastine and bleomycin (PVB) in patients with disseminated disease (Einhorn and Donohue, 1977a, Einhorn and Donohue, 1977b, Einhorn and Donohue, 1977c). By adding cisplatin to vinblastine and bleomycin, remission rates were increased to nearly $80 \%$, beginning the modern chemotherapy era for GCTs. Following the introduction of cisplatin, a major emphasis of research in GCT between 1980 and 2000 concentrated on establishing clinical factors capable of distinguishing which patients were likely and which were unlikely to be cured with standard chemotherapy. These efforts culminated in the publication of the International Germ Cell Cancer Collaborative Group (IGCCCG) risk classification system, which separates patients into good, intermediate-, and poor-risk groups with expected durable remission rates of $90 \%, 70 \%$, and $40 \%$, respectively (1997). Important prognostic factors in this system include seminomatous vs. nonseminomatous histology, sites of metastatic disease, levels of tumor markers, and primary tumor site (mediastinum vs. retroperitoneal/gonadal). Concurrent and subsequent efforts focused on reducing the toxicity of chemotherapy programs for good-risk patients and improving the efficacy of treatment for intermediate- and poor-risk patients. A series of successive well-designed and well-executed clinical trials led to the establishment of 4 cycles of etoposide (EP) plus cisplatin (EPx4) and 3 cycles of EP plus bleomycin (BEP) as standard first-line treatment programs for patients with good-risk GCTs. For intermediate- and poor-risk GCTs, BEPx4 has emerged as the standard-ofcare for first-line treatment. Nevertheless, despite these excellent regimens, up to $30 \%$ of patients will fail to be cured with first-line chemotherapy, including $50 \%$ of poor-risk patients. Nevertheless, the ability to cure such a high proportion of patients with widely metastatic disease renders GCTs unique amongst solid tumors. For this reason TGCT-derived cell lines and tumor specimens have been studied extensively in an attempt to identify the molecular characteristics underlying cisplatin sensitivity. Although complete mechanisms are not yet clear, recent studies have demonstrated a fundamental role for both the enhanced responsiveness of TGCTs to $553-$ mediated apoptosis induced by DNA damage, and reduced ability of TGCTs to repair cisplatin-induced DNA damage (see below). These characteristics are almost certainly inherited from the cells of origin (PGCs/gonocytes) since cisplatin sensitivity inversely correlate with the degree of differentiation. In fact while PGCs are particularly prone to cope with DNA damage by inducing apoptosis within irreparably damaged cells (Katayama et al., 2002) the loss of embryonic features as observed in mature teratomas, correlates 
with increased cisplatin resistance. Teratomas are considered completely insensitive to chemotherapy and therefore often are found within the pathologic specimens of residual tumor masses surgically resected after completion of chemotherapy. In vitro studies have confirmed that the relationship between differentiation and cisplatin-resistance. For example, when the pluripotent EC cell lines, NTERA-2D1 (NT2/D1) and Tera-2 are induced towards terminal differentiation by treatment with retinoic acid, these cells lose their hypersensitivity to cisplatin treatment, (Andrews, 1984, Timmer-Bosscha et al., 1998) even after only 48hs of stimulation (Gutekunst et al., 2011). Surgical resection of residual teratomas is of clinical relevance. In fact, while teratomas can be biologically inert; they undergo malignant transformation in $6 \%$ to $14 \%$ of the cases, underlying the importance of identifiying of new less-invasive therapies (i.e. chemotherapies) for their eradication.

\section{Molecular mechanisms of TGCT sensitivity}

\section{Mechanisms of drug access to DNA and detoxification}

In order to reach its molecular target (DNA), cisplatin must first gain access to the cell via transport across the cell membrane and escape inherent cellular detoxification processes. Comparison of cisplatin-sensitiveTGCT cell lines with relatively cisplatinresistant colon and bladder cancer cell lines did not reveal any significant difference in cisplatin accumulation (Sark et al., 1995), or cellular detoxification mechanisms, such as that involving the glutathione-S-transferase (Masters et al., 1996, Sark et al., 1995) or metallothionein (Masters et al., 1996, Meijer et al., 2000). More recently, we demonstrated that in EC cell lines, cisplatin-induced damage, as measured by $\gamma \mathrm{H} 2 \mathrm{AX}$ staining (a surrogate marker of DNA double strand break [DSB] formation) is not significantly different from that of the relatively cisplatin-resistant cell line U2OS (Cavallo et al., 2012). A similar finding was reported by Usanova and co-workers using different TGCT cell lines in an experimental setting (Usanova etal., 2010). Overall these results indicate that the increased responsiveness of EC cell lines to cisplatin is not related to upstream events that control drug-access to DNA, and rather, suggest downstream events, namely the DNA-damage response, as the potential etiology of cisplatin sensitivity among TGCTs.

\section{DNA-damage response}

The DNAdamage response (DDR) is a complex cellular process that detects DNAlesions, signals their presence and promotes their repair, enabling the preservation of genomic integrity. This system is linked to another important mechanism of maintaining DNA integrity, whereby if DNA damage is too great or repair is ineffective, cellular death pathways, such as apoptosis, are stimulated to combat the threats posed by excess or unrepaired DNA damage. Thus a reduction in the DNA-repair proficiency or the increased sensitivity to pro-apoptotic stimuli are potential mechanisms to explain the unique sensitivity of TGCT to cisplatin.

\section{The role of p53 in TGCT response to treatment}

The tumor suppressor protein p53 has been shown to mediate cellular stress responses in that p53 can initiate DNA repair, cell-cycle arrest, senescence and notably apoptosis (Levine, 1997, Prives and Hall, 1999). These responses suppress tumor formation. Thus it is not surprising that many solid tumors have p53 mutations (Greenblatt et al., 1994, Levine, 1997). Surprisingly however, p53 mutations are infrequent in TGCTs (Kersemaekers et al., 2002, Lutzker, 1998, Peng et al., 1993). This has suggested that an intact p53 pathway is responsible for the exquisite apoptotic response of TGCTs to DNA-damage, although not all tumors are equally responsive.

The absence of inactivating mutations in TP53 has been attributed to multiple factors. Comparison of TGCTs with tumors of somatic origin has shown that TGCTs lack constitutive activation of the DDR, which in somatic tumors functions as a barrier to tumor formation and growth in early stages of cancer development. Thus, TGCTs avoid the pressure to select for mutations in DDR genes, such as p53 (boxA in Fig. 1), Ataxia Telangiectasia Mutated (ATM) and Ataxia Telangiectasia and Rad3-related Protein (ATR) (Bartkova et al., 2007). Congruent with this observation, ATM and ATR pathways have been demonstrated to be intact in several TGCT cell lines (Usanova et al., 2010).

Many tumors that retain wild-type p53 (wtp53) still have dysfunctional p53-related DNA repair and apoptosis, typically due to other defects in the p53 pathway. In agreement with this notion, it has been found that in seminomas and in the EC component of nonseminomas carrying a wt p53, miR372/373 expression is upregulated (Box A in Fig. 1). These miRs target the Large Tumor Suppressor Homolog 2 (LATS2) serine-threonine kinase, and allow cell proliferation irrespective of p53 activation and p21 induction; thus also reducing the pressure for TRP53 mutations (Voorhoeve et al., 2006).

Reduced functionality of p53 in some TGCTs has also been attributed to Mouse Double Minute 2 Homolog (MDM2), a major physiological antagonist of p53. MDM2 is an E3 ubiquitin ligase that promotes p53 proteosomal degradation. Additionally, MDM2 can bind the p53 transactivation domain, thereby also directly interfering with p53 transcriptional regulatory mechanisms. In most tumors retaining wtp53, MDM2 plays an important role in suppressing p53 activity. This is often caused by, overexpression of MDM2, and silencing of the MDM2 regulator ADP Ribosylation Factor (ARF). Because gain of MDM2 expression and ARF mutations are associated with TGCT development (Datta et al., 2001, Iwato et al., 2000), it has been suggested that in TGCTs, MDM2 functional hyperactivation might suppress p53 function (Box A in Fig. 1). In line with this hypothesis, the comparison of different TGCT cell lines with a wide difference in their relative resistance to cisplatin, have shown that the reduced p53-induced apoptotic response observed in cisplatin-resistant TGCT cell lines, is linked to sustained MDM2-p53 complex formation (Koster et al., 2011). This indicates that in these cells, MDM2 inhibits p53-pro-apoptotic function and promotes cisplatin-resistance. In keeping with this observation, treatment of TGCT cell lines with the MDM2-inhibitor, nutlin-3, caused a strong increase in p53 protein level, and promoted p53 pro-apoptotic function, including in cell lines relatively resistant to cisplatin (B in Fig.1; Bauer et al., 2009, Koster et al., 2011, Li et al., 2010) although not all cisplatin-resistant tumors were equally responsive (Li et al., 2010). In addition to MDM2, the expression of the MDM2 -homolog MDMx also contributes to inactivation of wt-p53, although the effect was found to be of minor importance (Li et al., 2010).

The pivotal role of p53 pro-apoptotic function in the sensitivity of TGCTs to cisplatin has also recently been shown by studies demonstrating that siRNA-mediated silencing of p53 completely abrogates the response of EC cell lines to cisplatin (Gutekunst 
et al., 2011). In addition, comparison of the effects of cisplatin on EC cell lines to its effects on somatic tumor cells revealed that ECs exhibit a hypersensitive reaction to DNA-damage induced increases in p53 protein level via a brisk and strong apoptotic response (Gutekunst et al., 2011). EC are also hypersensitive to the increase in p53 protein level induced by nutlin-3 (Gutekunst et al., 2011, Koster et al., 2011). This result has suggested that regardless of how increased p53 protein level is achieved, EC cells respond by activating the p53-dependent pro-apoptotic pathway, causing rapid and massive cell death. Since nutlin-3 is expected to stabilize p53 in a non-genotoxic manner (B in Fig. 1)(Thompson et al., 2004), the hypersensitive response of EC cells to nutlin-3 also indicates that defects in DNA repair may not be required for EC hypersensitivity to cisplatin (Gutekunst et al., 2011). In addition, when caspase-mediated apoptosis was inhibited in the EC cell line NT2D1 by treatment with Benzyloxycarbonyl-Val-AlaAsp(OMe)-fluoromethylketone (zVADfmk), cells were able to repair cisplatin-induced damage. This suggested that under genotoxic conditions, cisplatin-induced p53-pro-apoptotic response precedes DNA-damage repair, and it is thus the primary cause of TGCT sensitivity to the drug (Gutekunst et al., 2011). However, using $\gamma \mathrm{H} 2 \mathrm{AX}$

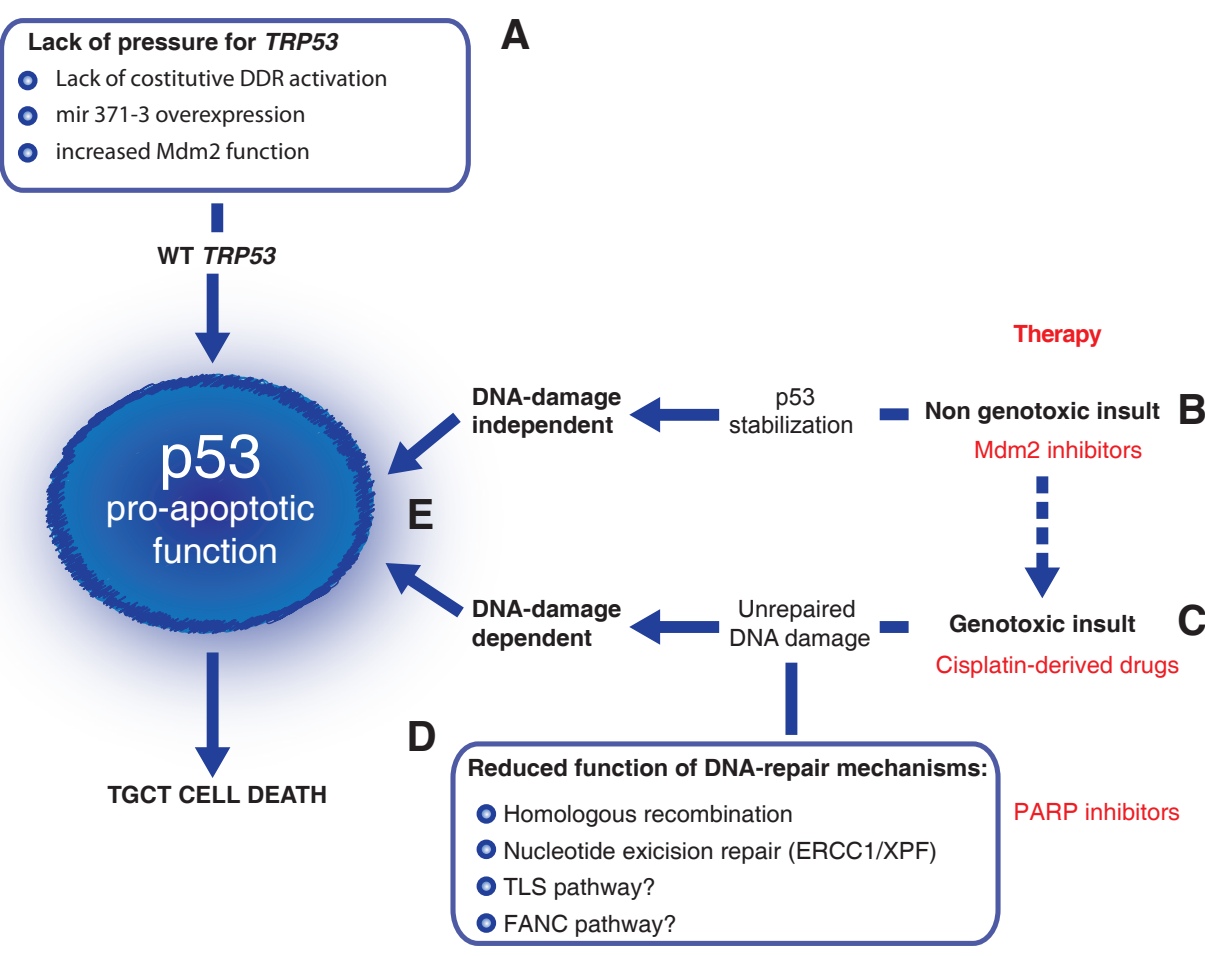

Fig.1.The testicular germ cell tumor $\mathrm{p53}$-pro apoptotic response is promoted by both genotoxicdependent and independent mechanisms. (A) Molecular mechanisms that, in TGCTs, reduces the selective pressure for TRP53 mutations (see text for details). (B) Nutlin-3 treatment prevents p53/ MDM2 binding and stabilize p53 promoting its pro-apoptotic function. (C) The treatment of TGCT cell lines with the genotoxic drug cisplatin, causes DNA damage, promoting a DNA-damage dependent release of p53 by MDM2, and cell death. (D) TGCT cells have a reduced proficiency in the repair of ICLs induced by cisplatin. Such defect is due to a reduced function of multiple DNA repair pathways, including NER and HR pathways. Whether other DNA-repair pathways, such as TLS and FA are also defective is still unknown. (E) non-genotoxic (nutlin-3) and genotoxic (cisplatin) drugs cooperate to promote p53 pro-apoptotic function (see text for more details). In red are indicated some of the chemical compounds known to stabilize p53 (nutlin-3), induce DNA damage (cisplain) or enhance DNA damage-induced cell death in HR-deficient cells (PARP inhibitors). The dotted arrow indicates the contribution of genotoxic-damage induced by nutlin-3, in TGCT apoptotic response. Abbreviations: DDR, DNA damage response; miR, micro RNA; TLS, translesion synthesis; FANC, Fanconi anemia. as a marker of DSBs, we found that prevention of the apoptotic response by zVADfmk, did not rescue the ability of NT2D1 cells to ( s]) (Cavallo et al., 2012). These discrepant results could likely preferentially detectintrastrand crosslinks (which accou kely preferentially detect intrastrand crosslinks (which account for 11). 2011). TGCTs have been reported to be proficient in intrastrand this conclusion. Considering our observations, we propose that the extreme sensitivity of EC to cisplatin, the cells to repair ICLs, is the trigger of such response ( $C$ in Fig. Ce al., 2012). Interestingly, it has been demonstrated resistant TGCT cell lines, the drug is not able to overcome cisplatin resistance and induce cell death in all cases ( $\mathrm{Li}$ et al., 2010). In contrast, a separate study demonstrated that when nutlin-3 and cisplatin were given in combination, the two drugs cooperated to all of the relatively-resistant TGCT cell lines tested (Koster et al., 2011). We interpret such cooperative effect, observed also in other studies (Bauer et al., 2009, Li et al., 2010), as indicating that, although DNA damage is not necessary per se to induce apoptosis in TGCT, it cooperates with nutlin-3 in the release of the negative feedback that constrain p53 pro-apoptotic function, likely further inhibiting MDM2-p53 complex formation. This might be due to MDM2 phosphorylation by the DDR transducers ATM, ATR and DNA-PK (Chehab et al., 1999, Shieh et al., 1997) and/or the reduced steady state level of MDM2 induced by the genotoxic treatment in TGCT cells (Li et al., 2010). It should also be noted that in some cellular contexts nutlin-3 treatment of somatic tumor cell lines might have genotoxic effects, as it induces the activation of the DDR and formation of $\gamma \mathrm{H} 2 \mathrm{AX}$ foci (Valentine et al., Verma et al., 2010). Although still controversial, such ability seems to be independent of p53 status, and unrelated to the role of nutlin-3 as MDM2 antagonist (Valentine et al., 2011, Verma et al., 2010). Using Flow cytometry, we extended these observations to TGCTs and found that, in the EC cell lines 2102Ep, Tera-1 and NT2D1, though nutlin-3 treatment induced a comparable stabilization of p53 protein (Fig 2A), the magnitude of their apoptotic response was not uniform (Fig. 2B). In fact the percentage of apoptotic cells (sub G1 fraction) was higher in 2102Ep and Tera-1 cell lines than in NT2D1 (Fig. 2B). Interestingly, this differential response correlated with an increased $\gamma \mathrm{H} 2 \mathrm{AX}$ staining in 2102Ep and Tera-1 (Fig 2C). Although this observation 
requires further experimental investigations, it suggests that, as in other cellular systems, in some TGCT cell lines nutlin-3 treatment can also cause DNA damage (dotted arrow in Fig.1). As such, nutlin-3 cannot be used to absolutely distinguish between a DNA-damage independent or dependent p53-pro-apoptotic responses. In addition, we propose that the limited nutlin-3-induced apoptotic response observed in some cisplatin-resistant cell lines (Li et al., 2010) might reflect the lack of DNA damage induction by nutlin-3 in some cellular contexts, or an increased proficiency of the DNA repair mechanisms, if damage is induced. Altogether, these observations indicate that under genotoxic conditions, DNA damage induction/persistence is the trigger for TGCT activation of the p53-mediated pro-apoptotic function (Fig. 1C). Although p53-dependent apoptosis can be simply induced by increasing p53 protein level, DNA-damage induction/persistence likely acts as an additional layer of control over p53-pro apoptotic function, further promoting cell death (Fig. 1E). In this context variations in the proficiency of DNA repair mechanism might significantly influence the magnitude of the response to cisplatin (and perhaps nutlin-3) treatment, promoting a massive apoptotic response in DNA-damage repair deficient cells (box D in Fig. 1), or increasing resistance if DNA repair proficiency is improved.

\section{Mechanisms of interstrand crosslink repair}

The formation of DNAinterstrand cross-links (ICLs) lesion causes replication fork stalling during the S-phase of the cell cycle, which is removed through a replication-dependent homology-direct repair mechanism. The latter requires the coordinated action of a complex set of DNA repair factors, including those involved in homologous recombination (HR), Translesion synthesis (TLS), excision repair cross-complementing rodent repair deficiency, complementation group 1 and 4 protein factors (ERCC1 and ERCC4[XPF]), and Fanconi anemia (FA) proteins.

$\mathrm{HR}$, also termed homology-direct repair, typically occur in S-phase and uses the identical sister chromatid to restore the original sequence prior to DNA damage. It plays an essential function in supporting faithful duplication of the genome and telomere maintenance in normal cells, but also has a prominent function in preserving genome integrity, as it provides a high-fidelity repair or tolerance of complex DNA damages (including DNA gaps, DNA DSBs and ICLs) which arise either spontaneously, or are induced by drugs treatment, (Li and Heyer, 2008). Highlighting an important

Fig. 2. Nutlin-3 treatment of testicular germ cell tumor cell lines promotes H2AX phosporylation. (A) nutlin-3 treatment induces p53 stabilization. The indicated cell lines were treated with $10 \mu \mathrm{M}$ nutlin-3 for 20hs, and analyzed by western blotting for p53 expression. NCCIT cells (which express a truncated and inactive p53) were used as negative control. Tubulin was used as loading control. (B) Nutlin-3 treatment promotes TGCT apoptotic response. The indicated cell lines were treated as in A and collected for Flow cytometry analysis of the sub-G1 fraction as previously described (Cavallo et al., 2012). Results are presented as percentage of sub-G1 cells/total. Data are mean values \pm s.d. of three independent experiments. (C) Nutlin-3 induces $\gamma \mathrm{H} 2 \mathrm{AX}$ phosphorylation. Flow cytometry analyse of $\gamma \mathrm{H} 2 \mathrm{AX}$ positive cells following nutlin-3 treatment. The indicated cell lines were treated as in $A$, and stained with $\gamma H 2 A X$ antibody as previously described (Cavallo et al., 2012). Results are presented as percentage of $\gamma \mathrm{H} 2 \mathrm{AX}$-positive cells/total. The total population of $\gamma \mathrm{H} 2 \mathrm{AX}$-positive doesn't include dead (sub-G1 stage) cells. Data are mean values \pm s.d. of three independent experiments. role in the repair of spontaneously arising DNA damage, cells with HR defects exhibit a high frequency of chromosome aberrations (Pierce et al., 1999). In the context of cancer therapy, of particular interest is the induction of DNA damage by exogenous sources. Ionizing irradiation as well as bleomycin, neocarcinostatin, etoposide and camptothecin promotes (with different mechanisms) DSB formation. HR-deficient cells such as breast cancer genes (BRCA) BRCA1 and BRCA2 deficient cells are hypersensitive to these drugs, underlying the importance of this pathway for DSB repair (Moynahan etal., 2001a). BRCA1 and BRCA2 mutant cells (among others) are also defective in the repair of frank DSBs introduced within a reporter substrate (Moynahan et al., 1999, Moynahan et al., 2001b) indicating that DSBs are indeed the critical DNA lesion in these cells. In eukaryotes, DSBs have been also found to be a pivotal intermediate in the repair of ICLs (Al-Minawi et al., 2009). As such the loss of HR mediator proteins leads to a marked increase of the sensitivity to ICL-inducing agents such as psoralen, mitomycin C and cisplatin (Hanlon Newell et al., 2008, Moynahan et al., 2001a, Takata et al., 2001, Thacker, 2005). High sensitivity to ICL agents is also a hallmark of cells derived from FA patients (Wang and Gautier, 2010). FA is an inherited disease caused by the mutation of at least one of 13 gene products (FANCA, $-B,-C$, $D 1,-D 2,-E,-F,-G,-I,-J,-L,-M$, and $-M$ ). Among these proteins, FANCD1 is identical to BRCA2; thus FANCD1 cells are markedly defective in HR (Moynahan et al., 2001b, Nakanishi et al., 2005). However other FA cells are only mildly defective in the repair of frank DSBs (Nakanishi et al., 2005). This indicates that while FA proteins do not play a major role in the repair of DSBs per se, they do maintain a specific function in the execution of HR repair in the

A

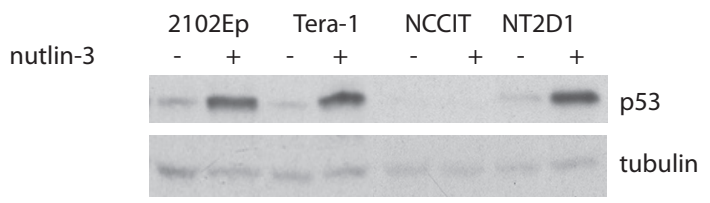

B

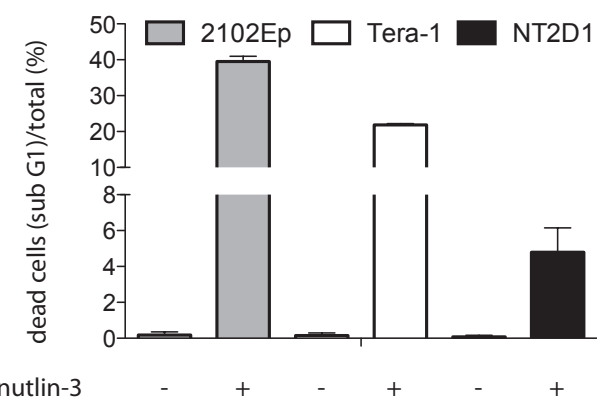

C

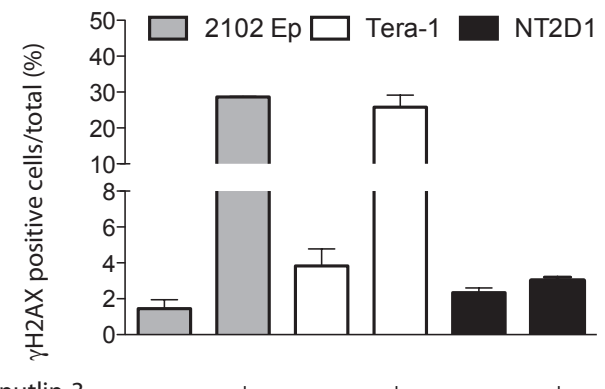

nutlin-3 
context of ICL damage; which we found to be coupled to replication (Nakanishi et al., 2011). The FA pathway acts as a sentinel in the detection of ICL. Once ICL is encountered, the FA pathway is activated and signals downstream to activate the ATR/Chk1dependent checkpoint inducing the cell cycle arrest that promotes damage repair. The FA also executes ICL repair by coordinating the action of HR, TLS and NER. A central event in the pathway is the monoubiquitination of FANCD2 and $\mathrm{FANCl}$ which is mediated by a group of upstream FA proteins (FANCA, FANCB, FANCC, FANCE, FANCF, FANCG, FANCL, and FANCM) that are assembled into a large nuclear E3 ubiquitin ligase complex, termed the "FA core complex". The initial event that follow ICLs recognition, is thought to be followed by the incision of ICLs by serial or combined activities of nucleases, including XPF-ERCC1 and MUS81-EME1 (Hanada et al., 2006, Niedernhofer et al., 2004). These proteins cut one side of the damaged DNA, unhooking the ICL and leaving a gap. The gap is subsequently bypassed by TLS polymerases, followed by removal of the monoadducts, repairing of the gap. DSBs are thought to be a byproduct of the ICL repair process. Because of availability of homologous templates, DSBs are subsequently repaired by HR. Activated FANCD2/FANCI were shown to be required at multiple step in these processes, including the nucleolytic incision and the TLS-mediated bypass (Knipscheer et al., 2009) likely promoting the recruitment of protein factors at the ICL site. (Hanada et al., 2006, Knipscheer et al., 2009, Moldovan and D'Andrea, 2009, Niedernhofer et al., 2004)

In the following sections, we will highlight the mechanisms of ICL repair shown to be defective in cisplatin-sensitiveTGCTs, discussing the potential implications of their reduced proficiency for the development of future chemotherapeutics approaches.

\section{TGCTs are defective in DNA damage repair of ICL}

In addition to the role of p53-induced apoptotic response discussed earlier, another key aspect of tumor response to genotoxic insults lies in its ability to remove the DNA lesion. Studies of NER repair pathway in TGCTs revealed that TGCT cell lines are defective in this pathway, pointing to it as one of the causes of TGCT sensitivity to cisplatin treatment. The first study showing a defective NER in TGCT was reported by Bedford et al., in 1988. Using atomic spectroscopy and alkaline elution, Bedford demonstrated that following treatment with cisplatin, bladder cancer cells were able to repair most of the DNA damage, while TGCTs could not (Bedford et al., 1988). Some years later, Koberle and co-workers confirmed this observation (Koberle et al., 1997, Koberle et al., 1999, Koberle et al., 1996), and proposed that reduced NER proficiency was caused by the reduced expression of xeroderma pigmentosum, complementation group A (XPA), XPF and ERCC1 (Welsh et al., 2004); likely due to reduced translation of these proteins (McGurk et al., 2006). However, a later study found that increasing the level of XPA protein in cisplatin-sensitive TGCT cell lines was insufficient to induce resistance to cisplatin or ultraviolet (UV) damage (Koberle et al., 2008).. Interestingly however, different findings were observed for ERCC1-XPF proteins. In fact, when cisplatin-sensitive cells lines were transiently transfected with a bi-cistronic mammalian expression vector driving the expression of both ERCC1 and XPF, the proficiency of cisplatin-sensitive cell lines to repair ICLs was significantly increased, with a protective effect on apoptosis induction, although the effect was not dramatic (Usanova et al., 2010). Overall, these findings suggest a role for impaired DNA repair in the sensitivity of TGCTs to ICL-inducing agents, and holds potential for the development of clinically relevant strategies to target cisplatin-resistant tumors; by either developing drugs able to interfere with ERCC1-XPF and ERCC1-XPA proteinprotein interaction, or reduce the endonuclease activity of XPF.

Reduced proficiency in ERCC1-XPF function is not the only DNArepair defect observed in TGCTs. We recently found that, ERCC1 and XPF expression did not correlate with cisplatin sensitivity within a panel of $E C$ cell lines with a wide variation in cisplatin sensitivity (Cavallo et al., 2012), although ERCC1 protein levels were overall reduced. This prompted us to investigate wether $\mathrm{EC}$ were also defective in HR, a pathway involved in ICL-repair (see above). Using both a GFP-based assay that measures cellular proficiency to repair frank DSBs by HR, and a cisplatin-induced Rad51 foci formation assay, we found that in EC cell lines, a reduced proficiency of HR correlates with TGCT sensitivity to cisplatin. Since PARP inhibition has been reported to have a synthetic lethal effect on HR-deficient cells, we tested EC sensitivity to the PARP-inhibitor AZD2281. We found that EC cells were indeed sensitive to the AZD2281, likely because of the increased load of DNA damage induced by the PARP inhibitor treatment (Cavallo et al., 2012). More importantly, AZD2281 potentiated the effect of cisplatin, mostly in relativelyresistant cell lines, causing cell death. This indicates that the use of PARP-inhibitors might promote p53-mediated pro-apoptotic function in EC tumors relatively resistant to cisplatin (Fig. 1), perhaps inhibiting $\mathrm{HR}$ as proposed in other cellular systems (Hegan et al., 2010). Therefore, combining PARP inhibitor therapy with Cisplatin might be able to improve tumor responses, especially in patients resistant to cisplatin therapy. However further studies are require to confirm these hypotheses.

\section{Concluding remarks and future directions}

DNA damaging drugs such as cisplatin and etoposide are highly successful in curing GCTs; however up to $30 \%$ of patients with advanced disease do not achieve a durable remission with first-line chemotherapy. In fact, although some of these men can be cured with salvage chemotherapy, approximately half will die from this disease. These are young patients, typically in the prime of their lives and as such, when death from GCT occurs, it accounts for the largest average number of life years lost of any adult malignancy (1999). Thus the identification of new therapeutic strategies is needed.

As outlined in this review, an improved understanding of cisplatin sensitivity and resistance is beginning to emerge. Reduced proficiency in DNA damage repair and enhanced induction of apoptosis appear to be the key factors underlying the sensitivity of TGCTs to cisplatin. Recent identification of alterations in specific proteins and pathways that contribute to the unique DNA repair and apoptosis phenotype of TGCTs have renewed interest in the development of rational novel therapies for cisplatin-resistant GCTs. For example, the use of MDM2 inhibitors appears to represent one potentially promising approach based on cell culture experiments demonstrating a subset of cisplatin-resistant cell lines respond to nutlin-3 treatment (Li et al., 2010). In addition, MDM2 inhibitors have been found to cooperate with cisplatin-induced damage in promoting TGCT cell death (Koster et al., 2011) suggesting that combining MDM2 inhibition and cisplatin holds additional promise ( $B, C, E$ in Fig. 1). MDM2 inhibitors have recently entered phase I 
clinical trials in haematological malignancies and solid tumors, with additional molecules in this class under preclinical study (Wang and $\mathrm{Hu}, 2012)$. If successful, combination studies with cisplatin would be anticipated to follow shortly behind these initial trials.

Recent identification of the reduced proficiency of EC in HR repair indicates PARP inhibitors as another potentially promising treatment for these tumors. Our demonstration of the sensitivity of resistant ECs to PARP-inhibitor monotherapy and combined therapy with cisplatin places this class of drugs in an ideal position for further testing prospectively in phase I and II trials of patients with cisplatin-resistant GCT. In addition, these results encourage extension of these analyses to in vitro testing of more differentiated TGCT tumors (teratomas) which are uniformly resistant to cisplatin as well as other cisplatin-resistant tumors with wtp53. Despite these results, further efforts are needed to uncover the mechanisms that underline EC deficiency in HR and ICL repair, including evaluation of the expression and function of TLS and FA proteins (Box D in Fig. 1). The next several years of research should prove highly fruitful as the mystery of GCT sensitivity to cisplatin continues to unravel.

\section{Acknowledgements}

This work was supported by Associazione Italiana per la Ricerca sul Cancro (AIRC grant n. 4765 to MB) and from Ministry of Education, Universities and Research of Italy (Cooperlink grant 2011, n. CII11RLETZ, PRIN 2010-2011, n. 2010M4NEFY_004, to MB). F.C. was supported by Byrne Foundation.

\section{References}

(1997). International Germ Cell Consensus Classification: a prognostic factor-based staging system for metastatic germ cell cancers. International Germ Cell Cancer Collaborative Group. J Clin Oncol 15: 594-603.

(1999). Stat bite: Average years of life lost per person dying of cancer. J Natl Cancer Inst 91: 1275.

AL-MINAWI, A.Z., LEE, Y.F., HAKANSSON, D., JOHANSSON, F., LUNDIN, C., SALEH-GOHARI, N., SCHULTZ, N., JENSSEN, D., BRYANT, H.E., MEUTH, M. et al., (2009). The ERCC1/XPF endonuclease is required for completion of homologous recombination at DNA replication forks stalled by inter-strand crosslinks. Nucleic Acids Res 37: 6400-6413.

ANDERSON, P.D., LAM, M.Y., POIRIER, C., BISHOP, C.E. and NADEAU, J.H. (2009). The role of the mouse y chromosome on susceptibility to testicular germ cell tumors. Cancer Res 69: 3614-3618.

ANDREWS, P.W. (1984). Retinoic acid induces neuronal differentiation of a cloned human embryonal carcinoma cell line in vitro. Dev Biol 103: 285-293.

BARTKOVA, J., RAJPERT-DE MEYTS, E., SKAKKEBAEK, N.E., LUKAS, J. and BARTEK, J. (2007). DNA damage response in human testes and testicular germ cell tumours: biology and implications for therapy. Int J Androl 30: 282-291; discussion 291.

BAUER, S., MUHLENBERG, T., LEAHY, M., HOICZYK, M., GAULER, T., SCHULER, M. and LOOIJENGA, L. (2009). Therapeutic potential of Mdm2 inhibition in malignant germ cell tumours. Eur Urol 57: 679-687.

BEDFORD, P., FICHTINGER-SCHEPMAN, A.M., SHELLARD, S.A., WALKER, M.C., MASTERS, J.R. and HILL, B.T. (1988). Differential repair of platinum-DNAadducts in human bladder and testicular tumor continuous cell lines. Cancer Res 48:3019-24.

BOSL, G.J. and MOTZER, R.J. (1997). Testicular germ-cell cancer. N Engl J Med 337: 242-253.

CAVALLO, F., GRAZIANI, G., ANTINOZZI, A., FELDMAN, F., HOULDSWORTH, J., BOSL, G., CHAGANTI, R., MOYNAHAN, M., JASIN, M. and BARCHI, M. (2012). Reduced proficiency in homologous recombination underlies the high sensitivity of Embryonal Carcinoma Testicular Germ Cell Tumors to cisplatin and poly (ADPribose)polymerase inhibition. PLoS One 7: e51563.

CHEHAB, N.H., MALIKZAY, A., STAVRIDI, E.S. and HALAZONETIS, T.D. (1999).
Phosphorylation of Ser-20 mediates stabilization of human p53 in response to DNA damage. Proc Natl Acad Sci USA 96: 13777-13782.

DATTA, M.W., MACRI, E., SIGNORETTI, S., RENSHAW, A.A. and LODA, M. (2001). Transition from in situ to invasive testicular germ cell neoplasia is associated with the loss of p21 and gain of mdm-2 expression. Mod Pathol 14: 437-442.

EINHORN, L.H. and DONOHUE, J. (1977a). Cis-diamminedichloroplatinum, vinblastine, and bleomycin combination chemotherapy in disseminated testicular cancer. Ann Intern Med 87: 293-298.

EINHORN, L.H. and DONOHUE, J.P. (1977b). Chemotherapy for disseminated testicular cancer. Urol Clin North Am 4: 407-426.

EINHORN, L.H. and DONOHUE, J.P. (1977c). Improved chemotherapy in disseminated testicular cancer. $J$ Urol 117: 65-69.

FOSSA, S.D., CHEN, J., SCHONFELD, S.J., MCGLYNN, K.A., MCMASTER, M.L., GAIL, M.H. and TRAVIS, L.B. (2005). Risk of contralateral testicular cancer: a population-based study of 29,515 U.S. men. J Natl Cancer Inst 97: 1056-1066.

GREENBLATT, M.S., BENNETT, W.P., HOLLSTEIN, M. and HARRIS, C.C. (1994). Mutations in the p53 tumor suppressor gene: clues to cancer etiology and molecular pathogenesis. Cancer Res 54: 4855-4878.

GREENE, M.H., KRATZ, C.P., MAI, P.L., MUELLER, C., PETERS, J.A., BRATSLAVSKY, G., LING, A., CHOYKE, P.M., PREMKUMAR, A., BRACCI, J. etal., (2010). Familial testicular germ cell tumors in adults: 2010 summary of genetic risk factors and clinical phenotype. Endocr Relat Cancer 17: R109-R121.

GUTEKUNST, M., OREN, M., WEILBACHER, A., DENGLER, M.A., MARKWARDT, C., THOMALE, J., AULITZKY, W.E. and VAN DER KUIP, H. (2011). p53 hypersensitivity is the predominant mechanism of the unique responsiveness of testicular germ cell tumor (TGCT) cells to cisplatin. PLoS One 6: e19198.

HANADA, K., BUDZOWSKA, M., MODESTI, M., MAAS, A., WYMAN, C., ESSERS, J. and KANAAR, R. (2006). The structure-specific endonuclease Mus81-Eme1 promotes conversion of interstrand DNA crosslinks into double-strands breaks. EMBO J 25: 4921-4932.

HANLON NEWELL, A.E., HEMPHILL, A., AKKARI, Y.M., HEJNA, J., MOSES, R.E. and OLSON, S.B. (2008). Loss of homologous recombination or non-homologous end-joining leads to radial formation following DNA interstrand crosslink damage. Cytogenet Genome Res 121: 174-180.

HARTMANN, J.T., FOSSA, S.D., NICHOLS, C.R., DROZ, J.P., HORWICH, A., GERL, A., BEYER, J., PONT, J., FIZAZI, K., HECKER, H. et al., (2001). Incidence of metachronous testicular cancer in patients with extragonadal germ cell tumors. J Natl Cancer Inst 93: 1733-1738.

HEGAN, D.C., LU, Y., STACHELEK, G.C., CROSBY, M.E., BINDRA, R.S. and GLAZER, P.M. (2010). Inhibition of poly(ADP-ribose) polymerase down-regulates BRCA1 and RAD51 in a pathway mediated by E2F4 and p130. Proc Natl Acad Sci USA 107: 2201-2206.

IWATO, M., TACHIBANA, O., TOHMA, Y., ARAKAWA, Y., NITTA, H., HASEGAWA, M., YAMASHITA, J. and HAYASHI, Y. (2000). Alterations of the INK4a/ARF locus in human intracranial germ cell tumors. Cancer Res 60: 2113-2115.

KANETSKY, P.A., MITRA, N., VARDHANABHUTI, S., LI, M., VAUGHN, D.J., LETRERO, R., CIOSEK, S.L., DOODY, D.R., SMITH, L.M., WEAVER, J. et al., (2009). Common variation in KITLG and at $5 q 31.3$ predisposes to testicular germ cell cancer. Nat Genet 41: 811-815.

KANTO, S., HIRAMATSU, M., SUZUKI, K., ISHIDOYA, S., SAITO, H., YAMADA, S., SATOH, M., SAITO, S., FUKUZAKI, A. and ARAI, Y. (2004). Risk factors in past histories and familial episodes related to development of testicular germ cell tumor. Int J Urol 11: 640-646.

KATAYAMA, K., UENO, M., YAMAUCHI, H., NAKAYAMA, H. and DOI, K. (2002). Ethylnitrosourea-induced apoptosis in primordial germ cells of the rat fetus. Exp Toxicol Pathol 54: 193-196.

KERSEMAEKERS, A.M., MAYER, F., MOLIER, M., VAN WEEREN, P.C., OOSTERHUIS, J.W., BOKEMEYER, C. and LOOIJENGA, L.H. (2002). Role of P53 and MDM2 in treatment response of human germ cell tumors. J Clin Oncol 20: 1551-1561.

KNIPSCHEER, P., RASCHLE, M., SMOGORZEWSKA, A., ENOIU, M., HO, T.V., SCHARER, O.D., ELLEDGE, S.J. and WALTER, J.C. (2009). The Fanconi anemia pathway promotes replication-dependent DNA interstrand cross-link repair. Science 326: 1698-1701.

KOBERLE, B., GRIMALDI, K.A., SUNTERS, A., HARTLEY, J.A., KELLAND, L.R. and MASTERS, J.R. (1997). DNA repair capacity and cisplatin sensitivity of human testis tumour cells. Int J Cancer 70: 551-555. 
KOBERLE, B., MASTERS, J.R., HARTLEY, J.A. and WOOD, R.D. (1999). Defective repair of cisplatin-induced DNAdamage caused by reduced XPA protein in testicular germ cell tumours. Curr Biol 9: 273-276.

KOBERLE, B., PAYNE, J., GRIMALDI, K.A., HARTLEY, J.A. and MASTERS, J.R. (1996). DNA repair in cisplatin-sensitive and resistant human cell lines measured in specific genes by quantitative polymerase chain reaction. Biochem Pharmacol 52: 1729-1734.

KOBERLE, B., ROGINSKAYA, V., ZIMA, K.S., MASTERS, J.R. and WOOD, R.D. (2008). Elevation of XPA protein level in testis tumor cells without increasing resistance to cisplatin or UV radiation. Mol Carcinog 47: 580-586.

KORKOLA, J.E., HOULDSWORTH, J., BOSL, G.J. and CHAGANTI, R.S. (2009a). Molecular events in germ cell tumours: linking chromosome-12 gain, acquisition of pluripotency and response to cisplatin. BJU Int 104: 1334-1338.

KORKOLA, J.E., HOULDSWORTH, J., FELDMAN, D.R., OLSHEN, A.B., QIN, L.X., PATIL, S., REUTER, V.E., BOSL, G.J. and CHAGANTI, R.S. (2009b). Identification and validation of a gene expression signature that predicts outcome in adult men with germ cell tumors. J Clin Oncol 27: 5240-5247.

KOSTER, R., TIMMER-BOSSCHA, H., BISCHOFF, R., GIETEMA, J.A. and DE JONG, S. (2011). Disruption of the MDM2-p53 interaction strongly potentiates p53-dependent apoptosis in cisplatin-resistant human testicular carcinoma cells via the Fas/FasL pathway. Cell Death Dis 2: e148.

LEVINE,A.J. (1997). p53, the cellular gatekeeper for growth and division. Cell88:323-331.

LI, B., CHENG, Q., LI, Z. and CHEN, J. (2010). p53 inactivation by MDM2 and MDMX negative feedback loops in testicular germ cell tumors. Cell Cycle 9: 1411-1420.

LI, X. and HEYER, W.D. (2008). Homologous recombination in DNA repair and DNA damage tolerance. Cell Res 18: 99-113.

LILFORD, R., JONES, A.M., BISHOP, D.T., THORNTON, J. and MUELLER, R. (1994). Case-control study of whether subfertility in men is familial. BMJ 309: 570-573.

LOOIJENGA, L.H., GILLIS, A.J., STOOP, H., BIERMANN, K. and OOSTERHUIS, J.W. (2011). Dissecting the molecular pathways of (testicular) germ cell tumour pathogenesis; from initiation to treatment-resistance. Int J Androl 34: e234-e251.

LUTZKER, S.G. (1998). P53 tumour suppressor gene and germ cell neoplasia. APMIS 106: 85-89.

MASTERS, J.R., THOMAS, R., HALL,A.G., HOGARTH, L., MATHESON, E.C., CATTAN, A.R. and LOHRER, H. (1996). Sensitivity of testis tumour cells to chemotherapeutic drugs: role of detoxifying pathways. Eur J Cancer 32A: 1248-1253.

MCGLYNN, K.A. and COOK, M.B. (2009). Etiologic factors in testicular germ-cell tumors. Future Oncol 5: 1389-1402.

MCGLYNN, K.A., QURAISHI, S.M., GRAUBARD, B.I., WEBER, J.P., RUBERTONE, M.V. and ERICKSON, R.L. (2008). Persistent organochlorine pesticides and risk of testicular germ cell tumors. J Natl Cancer Inst 100: 663-671.

MCGURK, C.J., CUMMINGS, M., KOBERLE, B., HARTLEY, J.A., OLIVER, R.T. and MASTERS, J.R. (2006). Regulation of DNA repair gene expression in human cancer cell lines. J Cell Biochem 97: 1121-1136.

MEIJER, C., TIMMER, A., DE VRIES, E.G., GROTEN, J.P., KNOL, A., ZWART, N., DAM, W.A., SLEIJFER, D.T. and MULDER, N.H. (2000). Role of metallothionein in cisplatin sensitivity of germ-cell tumours. Int $J$ Cancer 85: 777-781.

MOLDOVAN, G.L. and D'ANDREA, A.D. (2009). FANCD2 hurdles the DNA interstrand crosslink. Cell 139: 1222-1224.

MOLLER, H. and SKAKKEBAEK, N.E. (1997). Testicular cancer and cryptorchidism in relation to prenatal factors: case-control studies in Denmark. Cancer Causes Control 8: 904-912.

MOYNAHAN, M.E., CHIU, J.W., KOLLER, B.H. and JASIN, M. (1999). Brca1 controls homology-directed DNA repair. Mol Cell 4: 511-518.

MOYNAHAN, M.E., CUI, T.Y. and JASIN, M. (2001a). Homology-directed dna repair, mitomycin-c resistance, and chromosome stability is restored with correction of a Brca1 mutation. Cancer Res 61: 4842-4850.

MOYNAHAN, M.E., PIERCE, A.J. and JASIN, M. (2001b). BRCA2 is required for homology-directed repair of chromosomal breaks. Mol Cell 7: 263-272.

NAKANISHI, K., CAVALLO, F., PERROUAULT, L., GIOVANNANGELI, C., MOYNAHAN, M.E., BARCHI, M., BRUNET, E. and JASIN, M. (2011). Homology-directed Fanconi anemia pathway cross-link repair is dependent on DNA replication. Nat Struct Mol Biol 18: 500-503.
NAKANISHI, K., YANG, Y.G., PIERCE, A.J., TANIGUCHI, T., DIGWEED, M., D'ANDREA, A.D., WANG, Z.Q. and JASIN, M. (2005). Human Fanconi anemia monoubiquitination pathway promotes homologous DNArepair. Proc NatlAcad SciUSA 102: 1110-1115.

NIEDERNHOFER, L.J., ODIJK, H., BUDZOWSKA, M., VAN DRUNEN, E., MAAS, A., THEIL,A.F., DE WIT, J., JASPERS, N.G., BEVERLOO, H.B., HOEIJMAKERS, J.H. et al., (2004). The structure-specific endonuclease Ercc1-Xpf is required to resolve DNA interstrand cross-link-induced double-strand breaks. Mol Cell Biol 24: 5776-5787.

PENG, H.Q., HOGG, D., MALKIN, D., BAILEY, D., GALLIE, B.L., BULBUL, M., JEWETT, M., BUCHANAN, J. and GOSS, P.E. (1993). Mutations of the p53 gene do not occur in testis cancer. Cancer Res 53: 3574-3578.

PIERCE, A.J., JOHNSON, R.D., THOMPSON, L.H. and JASIN, M. (1999). XRCC3 promotes homology-directed repair of DNA damage in mammalian cells. Genes Dev 13: 2633-2638.

PRENER, A., ENGHOLM, G. and JENSEN, O.M. (1996). Genital anomalies and risk for testicular cancer in Danish men. Epidemiology 7: 14-19.

PRIVES, C. and HALL, P.A. (1999). The p53 pathway. J Pathol 187: 112-126.

ROSENBERG, C., VAN GURP, R.J., GEELEN, E., OOSTERHUIS, J.W. and LOOIJENGA, L.H. (2000). Overrepresentation of the short arm of chromosome 12 is related to invasive growth of human testicular seminomas and nonseminomas. Oncogene 19: 5858-5862.

SARK, M.W., TIMMER-BOSSCHA, H., MEIJER, C., UGES, D.R., SLUITER, W.J., PETERS, W.H., MULDER, N.H. and DE VRIES, E.G. (1995). Cellular basis for differential sensitivity to cisplatin in human germ cell tumour and colon carcinoma cell lines. Br J Cancer 71: 684-690.

SHIEH, S.Y., IKEDA, M., TAYA, Y. and PRIVES, C. (1997). DNA damage-induced phosphorylation of $\mathrm{p} 53$ alleviates inhibition by MDM2. Cell 91: 325-334.

SKAKKEBAEK, N.E. (1972). Possible carcinoma-in-situ of the testis. Lancet2: 516-517.

TAKATA, M., SASAKI, M.S., TACHIIRI, S., FUKUSHIMA, T., SONODA, E., SCHILD, D., THOMPSON, L.H. and TAKEDA, S. (2001). Chromosome instability and defective recombinational repair in knockout mutants of the five Rad51 paralogs. Mol Cell Biol 21: 2858-2866

THACKER, J. (2005). The RAD51 gene family, genetic instability and cancer. Cancer Lett 219: 125-135.

THOMPSON, T., TOVAR, C., YANG, H., CARVAJAL, D., VU, B.T., XU, Q., WAHL, G.M., HEIMBROOK, D.C. and VASSILEV, L.T. (2004). Phosphorylation of p53 on key serines is dispensable for transcriptional activation and apoptosis. $J$ Biol Chem 279: 53015-53022.

TIMMER-BOSSCHA, H., DE VRIES, E.G., MEIJER, C., OOSTERHUIS, J.W. and MULDER, N.H. (1998). Differential effects of all-trans-retinoic acid, docosahexaenoic acid, and hexadecylphosphocholine on cisplatin-induced cytotoxicity and apoptosis in a cisplantin-sensitive and resistant human embryonal carcinoma cell line. Cancer Chemother Pharmacol 41: 469-476.

USANOVA, S., PIEE-STAFFA, A., SIED, U., THOMALE, J., SCHNEIDER, A., KAINA B. and KOBERLE, B. (2010). Cisplatin sensitivity of testis tumour cells is due to deficiency in interstrand-crosslink repair and low ERCC1-XPF expression. Mol Cancer 9: 248.

VALENTINE, J.M., KUMAR, S. and MOUMEN, A. (2011). Ap53-independent role for the MDM2 antagonist Nutlin-3 in DNA damage response initiation. BMC Cancer 11: 79

VERMA, R., RIGATTI, M.J., BELINSKY, G.S., GODMAN, C.A. and GIARDINA, C. (2010). DNA damage response to the Mdm2 inhibitor nutlin-3. Biochem Pharmacol 79: 565-574.

VOORHOEVE, P.M., LE SAGE, C., SCHRIER, M., GILLIS, A.J., STOOP, H., NAGEL, R., LIU, Y.P., VAN DUIJSE, J., DROST, J., GRIEKSPOOR, A. et al., (2006). A genetic screen implicates miRNA-372 and miRNA-373 as oncogenes in testicular germ cell tumors. Cell 124: 1169-1181.

WANG, L.C. and GAUTIER, J. (2010). The Fanconi anemia pathway and ICL repair: implications for cancer therapy. Crit Rev Biochem Mol Biol 45: 424-439.

WANG, W. and HU, Y. (2012). Small molecule agents targeting the p53-MDM2 pathway for cancer therapy. Med Res Rev 32: 1159-1196.

WELSH, C., DAY, R., MCGURK, C., MASTERS, J.R., WOOD, R.D. and KOBERLE, B. (2004). Reduced levels of XPA, ERCC1 and XPF DNA repair proteins in testis tumor cell lines. Int J Cancer 110: 352-3561.

WYLIE, C. (1999). Germ cells. Cell 96: 165-174. 


\section{Further Related Reading, published previously in the Int. J. Dev. Biol.}

Genome-wide gene expression analysis in mouse embryonic stem cells Juan Sainz, Fernando García-Alcalde, Armando Blanco and Ángel Concha Int. J. Dev. Biol. (2011) 55: 995-1006

Analysis of SOX2 expression in developing human testis and germ cell neoplasia Si B. Sonne, Rebecca M. Perrett, John E. Nielsen, Melissa A. Baxter, David M. Kristensen, Henrik Leffers, Neil A. Hanley and Ewa RajpertDe-Meyts

Int. J. Dev. Biol. (2010) 54: 755-760

Interplay between DNA methylation, histone modification and chromatin remodeling in stem cells and during development Kohta Ikegami, Jun Ohgane, Satoshi Tanaka, Shintaro Yagi, and Kunio Shiota

Int. J. Dev. Biol. (2009) 53: 203-214

Germinal tumor invasion and the role of the testicular stroma

Alejandro Díez-Torre, Unai Silván, Olivier De Wever, Erik Bruyneel, Marc Mareel and Juan Aréchaga Int. J. Dev. Biol. (2004) 48: 545-557

Germ cell biology--from generation to generation

P J Donovan, M P De Miguel, M P Hirano, M S Parsons and A J Lincoln Int. J. Dev. Biol. (2001) 45: 523-531

The role of stem cell factor and of alternative c-kit gene products in the establishment, maintenance and function of germ cells

C Sette, S Dolci, R Geremia and P Rossi

Int. J. Dev. Biol. (2000) 44: 599-608

Bone morphogenetic proteins (BMPs) induce epithelial differentiation of NT2D1 human embryonal carcinoma cells

ACaricasole, D Ward-van Oostwaard, LZeinstra, Avan den Eijnden-van Raaij and C Mummery Int. J. Dev. Biol. (2000) 44: 443-450

Changes in surface glycoconjugates in adhesion-defective variants of P19 embryonal carcinoma cells

M Sakalian and P Dráber

Int. J. Dev. Biol. (1991) 35: 473-479

Teratocarcinoma stem cells as a model for differentiation in the mouse embryo E Lehtonen, A Laasonen and J Tienari

Int. J. Dev. Biol. (1989) 33: 105-115

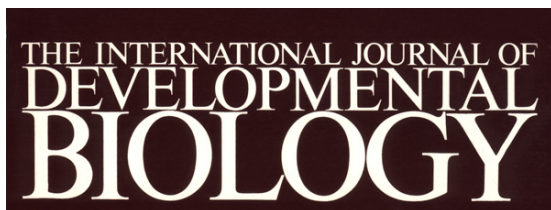

5 yr ISI Impact Factor $(2011)=2.959$
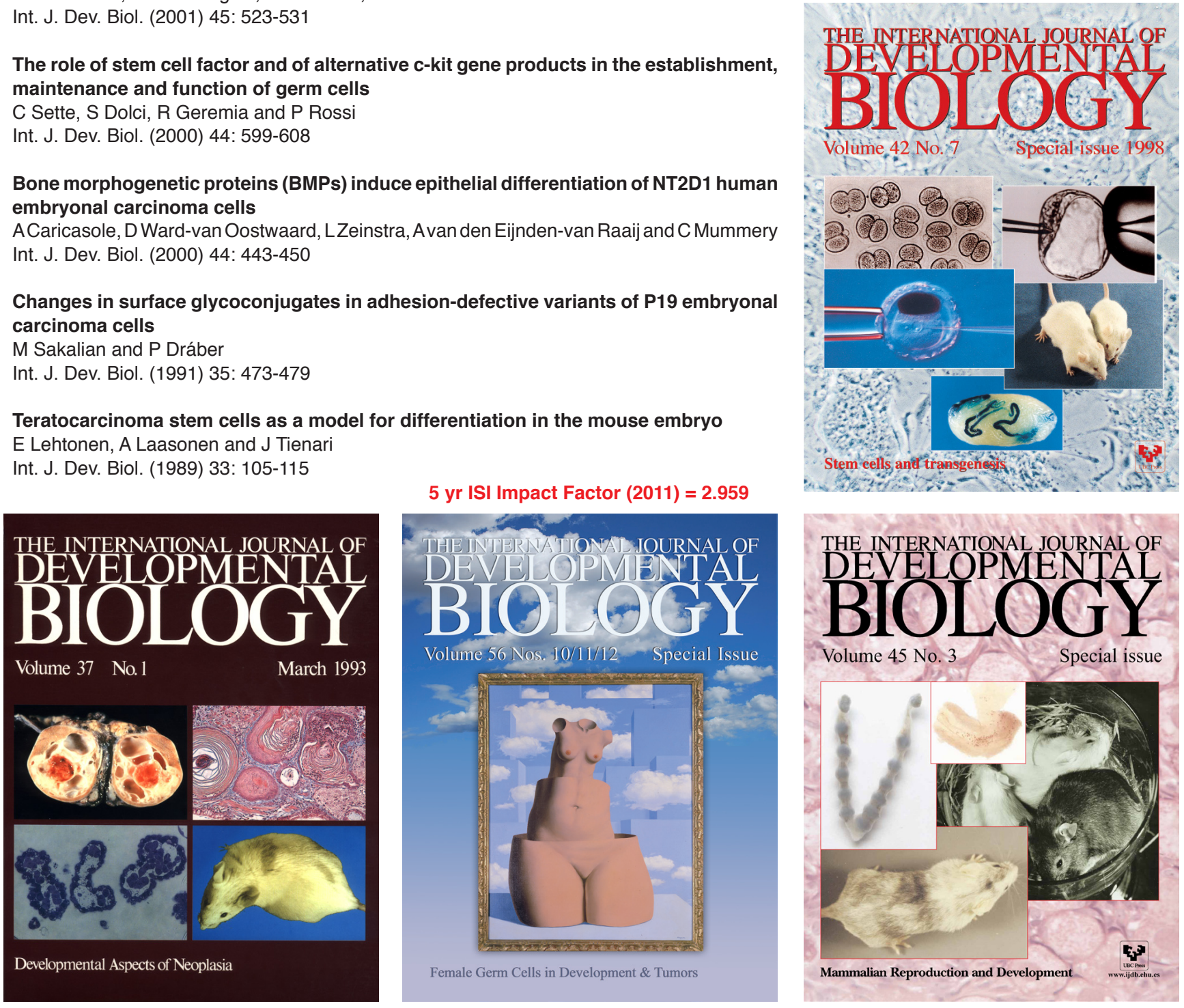